\title{
Strong and Stiff: High-Performance Cellulose Nanocrystal/Poly(vinyl alcohol) Composite Fibers
}

\author{
Won Jun Lee, ${ }^{\dagger}$ Adam J. Clancy, ${ }^{\dagger}$ Eero Kontturi, ${ }^{\ddagger},,, \|$ Alexander Bismarck, ${ }^{\S, \|}$ and Milo S. P. Shaffer ${ }^{*}, \dagger$
}

${ }^{\dagger}$ Nanostructured Hierarchical Assemblies and Composites Group (NanoHAC), Department of Chemistry, Department of Materials, and ${ }^{\S}$ Polymer and Composite Engineering (PaCE) Group, Department of Chemical Engineering, Imperial College London, South Kensington Campus, London SW7 2AZ, United Kingdom

${ }^{\ddagger}$ Department of Forest Products Technology, School of Chemical Technology, Aalto University, P.O. Box 16300, Aalto FI-00076, Finland

"Polymer and Composite Engineering (PaCE) Group, Institute of Materials Chemistry and Research, Faculty of Chemistry, University of Vienna, Währinger Strasse 42, A-1090 Vienna, Austria

\section{Supporting Information}
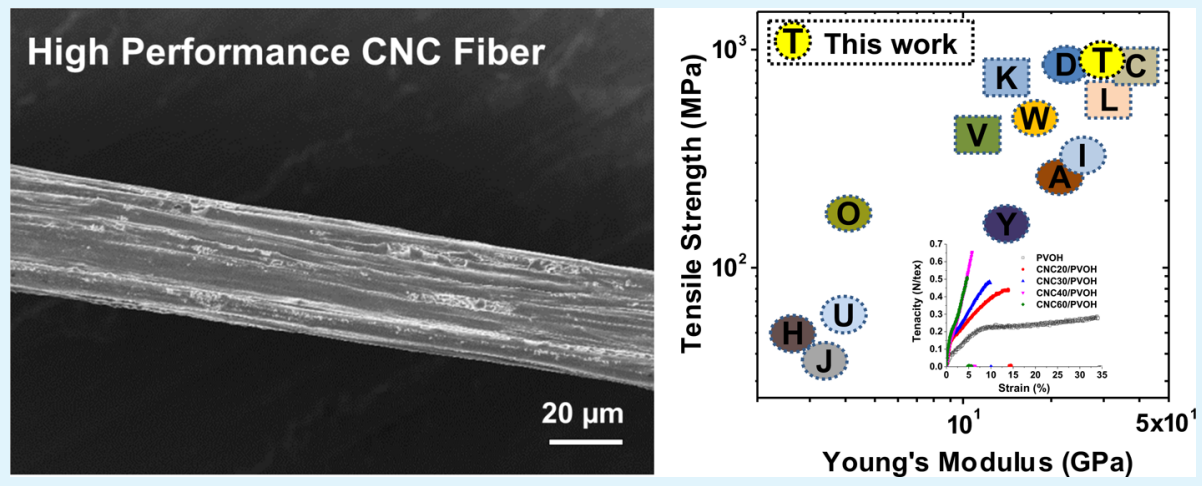

ABSTRACT: The mechanical properties of rodlike cellulose nanocrystals (CNCs) suggest great potential as bioderived reinforcement in (nano)composites. Poly(vinyl alcohol) (PVOH) is a useful industrial material and very compatible with CNC chemistry. High performance $\mathrm{CNC} / \mathrm{PVOH}$ composite fibers were produced coaxial coagulation spinning, followed by hotdrawing. We showed that CNCs increase the alignment and crystallinity of PVOH, as well as providing direct reinforcement, leading to enhanced fiber strength and stiffness. At $40 \mathrm{wt} \% \mathrm{CNC}$ loading, the strength and stiffness reached $880 \mathrm{MPa}$ and 29.9 $\mathrm{GPa}$, exceeding the properties of most other nanocellulose based composite fibers previously reported.

KEYWORDS: nanocellulose, cellulose nanocrystal, poly vinyl alcohol, composite, fiber

ellulose nanocrystals (CNCs) are short rigid single crystals of cellulose, generally with a width of ca. 5-20 $\mathrm{nm}$ and length of $100-300 \mathrm{~nm}^{1}$ Their straight rodlike morphology is characteristic, and distinguishes them from longer, typically entangled, cellulose nanofibers (CNFs), which represent the other important member of the nanocellulose family. Cellulose is the principal component in all plants and is the most abundant renewable polymer on earth. The ideal crystalline form intrinsically possesses a very high strength $(\sim 7.6 \mathrm{GPa})$ and stiffness $(\sim 160 \mathrm{GPa})$ coupled with low density $\left(\sim 1.6 \mathrm{~g} / \mathrm{cm}^{3}\right){ }^{2}$ The other attractive features of CNCs, including biocompatibility, biodegradability, and sustainability, have stimulated a diverse range of potential applications including cosmetics, medical implants, chiral templates for inorganic materials, and green composites. ${ }^{3,4}$

The opportunity to obtain high mechanical performance from a renewable material has recently spurred an intensive period of research for applications of CNCs as a reinforcement for polymers. ${ }^{5}$ Unfortunately, CNCs are only compatible with a few polymer matrices and usually aggregate when blended with other materials, leading to a reduction in polymer/CNC interfacial area, poor stress transfer, and stress-concentrating agglomerates. ${ }^{6}$ Surface modification, particularly covalent polymer grafting, ${ }^{7}$ can overcome the poor compatibility but the procedures are often laborious and hard to scale. An alternative approach is to make use one of the few intrinsically compatible polymers as a matrix. ${ }^{8}$ Poly(vinyl alcohol) (PVOH) is one such suitable candidate: it does not adsorb on cellulose in water ${ }^{9}$ but its hydroxyl groups hydrogen bond copiously with those of cellulose in the dry state. However, although a range of $\mathrm{CNC} / \mathrm{PVOH}$ composites have been prepared, for example by electrospinning $(\sim 50 \mathrm{MPa}),{ }^{10}$ cross-linking $(\sim 100 \mathrm{MPa}),{ }^{11}$ and liquid crystal microphase separation $(0.05 \mathrm{~N} /$ tex $),{ }^{12}$ mechanical performance is generally inferior compared to expectations.

Received: September 12, 2016

Accepted: November 4, 2016

Published: November 4, 2016 
In this paper, we exploit uniform $\mathrm{CNC} / \mathrm{PVOH}$ suspensions to prepare high strength nanocomposite fibers via a gel spinning method, followed by hot-drawing. This approach is effective for high CNC loading fractions with excellent dispersion and alignment (Figure 1), as required for mechanically superior composite fibers.

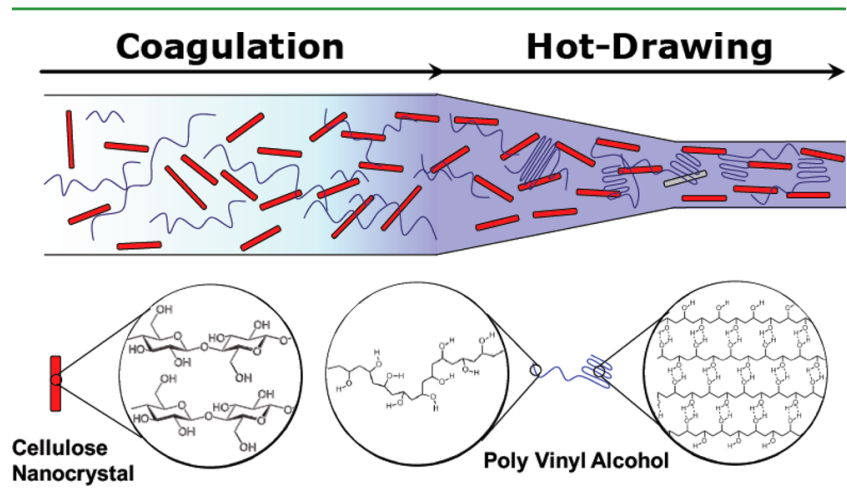

Figure 1. Illustration of fiber processing to optimize the microstructure of $\mathrm{CNC} / \mathrm{PVOH}$ composite fibers: (i) coagulation of spinning dope $(\mathrm{CNC}$ and $\mathrm{PVOH})$ by injection into a coaxial flowing stream of coagulant; (ii) hot-drawing of the fiber under tension at high temperature $\left(150^{\circ} \mathrm{C}\right)$.

Aqueous CNC suspensions (Figure 2a) were prepared by an established acid hydrolysis route, and mixed with $\mathrm{PVOH}$

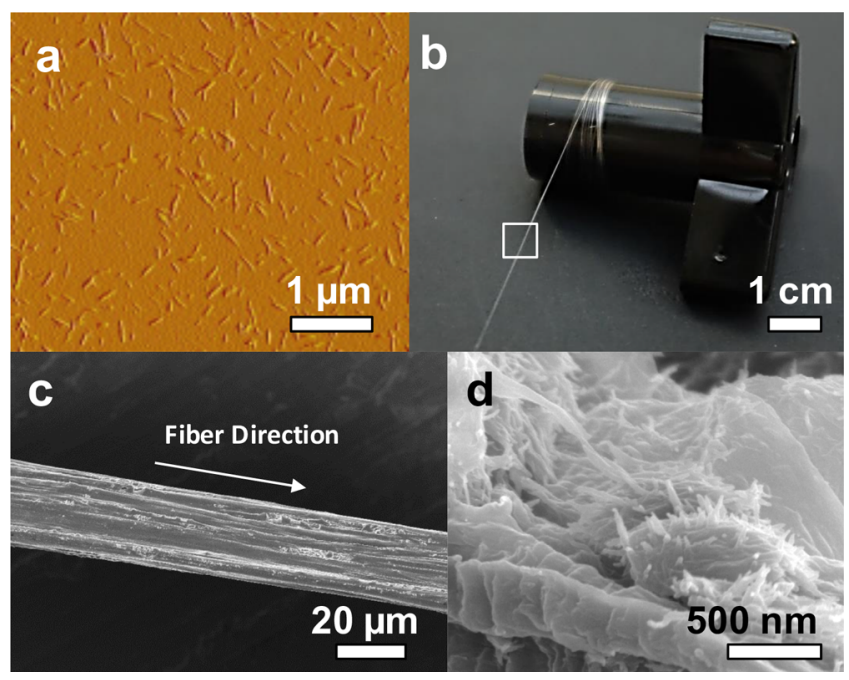

Figure 2. (a) $5 \times 5 \mu \mathrm{m}^{2}$ AFM height image of $20 \mathrm{mg} / \mathrm{mL} \mathrm{CNC}$ thin films. (b) $10 \mathrm{~m}$ long CNC fiber collected on a winder. SEM images of $\mathrm{CNC} 40 / \mathrm{PVOH}$ fiber, indicating a (c) well-formed fiber morphology and (d) dispersion of individual CNC rigid rods in PVOH matrix from $\mathrm{CNC} 40 / \mathrm{PVOH}$

solutions in DMSO, to form a uniform, stable spinning dope, with a final DMSO:water volume ratio of 4:1. Optical micrographs (Figure S1) show little evidence of agglomeration, due to the compatibility of the components, until the CNC content reaches around $60 \mathrm{wt} \%$ relative to $\mathrm{PVOH}$. Nanocomposite $\mathrm{CNC} / \mathrm{PVOH}$ fibers were successfully produced by injecting these spinning dopes into a coaxial flowing stream of antisolvent (acetone) to induce controlled coagulation. The coflowing antisolvent was intended to increase CNC alignment during the fiber spinning process and improve fiber consistency, by confining the gel filament in a laminar flow; this approach has previously been shown to be effective for carbon nanotubePVOH fibers. ${ }^{13}$ Around $1 \mathrm{~mL}$ of $\mathrm{CNC}$ spinning dope was coagulated and stretched during the spinning process to form a $\sim 2 \mathrm{~m}$ long fiber. Fibers were dried at ambient conditions then subsequently hot-drawn at $150{ }^{\circ} \mathrm{C}$, to a draw ratio of 6 , below the CNC degradation temperature of $200{ }^{\circ} \mathrm{C} .{ }^{14}$ Drawing the asspun fiber has two effects: it condenses the fiber and increases the alignment of both the CNC and polymer in the fiber direction, as can be seen by the increased birefringence (Figure S2) and X-ray diffraction patterns (see below). ${ }^{15}$ The final $\mathrm{CNC} / \mathrm{PVOH}$ composite fibers were $10 \mathrm{~m}$ in length (digital image, Figure $2 b$ ), with a linear density of $1.0 \pm 0.1$ tex (Figure 2c). Higher-magnification SEM images (Figure 2d) indicated that individual CNCs remained well dispersed in the composite at loadings up to $40 \mathrm{wt} \% \mathrm{CNCs}$. Indeed, good quality, dense, uniform fibers were obtained for the pure polymer and nanocomposites containing up to $40 \mathrm{wt} \% \mathrm{CNC}$. At $60 \mathrm{wt} \%$ $\mathrm{CNC}$, the fibers contained obvious agglomerates and pores (Figure S3).

The presence of nanofillers can alter the morphology of a polymer matrix as well as providing direct reinforcement; to help deconvolute these effects, polymer crystallinity and glass transition temperature $\left(T_{\mathrm{g}}\right)$ were quantified from the initial differential scanning calorimetry (DSC) heating scans (see Figure S4). ${ }^{3}$ After hot-drawing, the crystallinity of the $\mathrm{PVOH}$, calculated from the heat of fusion $\left(\Delta H_{\mathrm{m}}\right)$, increased steadily (Figure S4c) from 12.8 to $17.9 \%$ with increasing CNC loading. The increased $\mathrm{PVOH}$ crystallinity may be attributed to the dispersed, crystalline CNCs providing additional nucleation sites for PVOH during strain-induced crystallization. At the same time, the glass-transition temperature remained constant in the range of $70-72{ }^{\circ} \mathrm{C}$. (Figure S4)

The fiber microstructure was characterized by wide-angle $\mathrm{X}$ ray scattering (WAXS) to identify the crystal phases present and the degree of orientation of each component (Figure 3). Monoclinic syndiotactic $\mathrm{PVOH}$ has a unit cell ${ }^{6}$ with parameters $a=7.63 \AA, b=2.54 \AA$ (parallel to the chain axis), $c=5.41 \AA$, and $\gamma=91.5^{\circ}$. Predominantly, CNC has a cellulose $\mathrm{I}_{\beta}$ structure, ${ }^{17}$ which is monoclinic with parameters $a$ $=7.78 \AA, b=8.20 \AA, c=10.38 \AA$, and $\beta=96.5^{\circ}$. 1D WAXS (Figure S5) patterns of the fibers show the characteristic

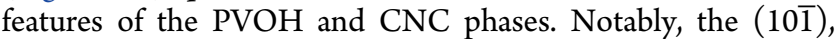
(101), and (200) planes of monoclinic PVOH and the (200) plane of monoclinic cellulose $\mathrm{I}_{\beta}$ crystal are observed. 2D X-ray patterns of the as-spun fibers show only approximately isotropic broad rings, indicating little preferential alignment of either PVOH or CNC (Figure S5 b-d). However, after hot-drawing, the $(10 \overline{1})$ and $(200)$ planes of the $\mathrm{PVOH}$ become much more intense in the equatorial region, indicating a high degree of orientation, with the fiber direction approximately parallel to the [010] direction (Figure 3a). The hot-drawn composite fibers containing 20 and $40 \mathrm{wt} \% \mathrm{CNC}$ show a similar trend but with even further improved alignment. The degree of orientation of $\mathrm{PVOH}$ was quantified from the full width at half-maximum (FWHM) of the azimuthal intensity distribution (fitted as Lorentzian functions) of the (101) plane of PVOH at $2 \theta=19.4^{\circ}$ (Figure 3, right). The hot-drawn pure $\mathrm{PVOH}$ fibers showed a preferred orientation $\left(\mathrm{FWHM}=39.5^{\circ}\right)$ along the fiber axis, similar to those reported previously. For both hotdrawn composite fibers, the $\mathrm{PVOH}$ crystallite orientation increased very significantly to around $\mathrm{FWHM}=18^{\circ}$ (Figure $3 \mathrm{~b}$, c). Unfortunately, the CNC (200) peak coincides with the 

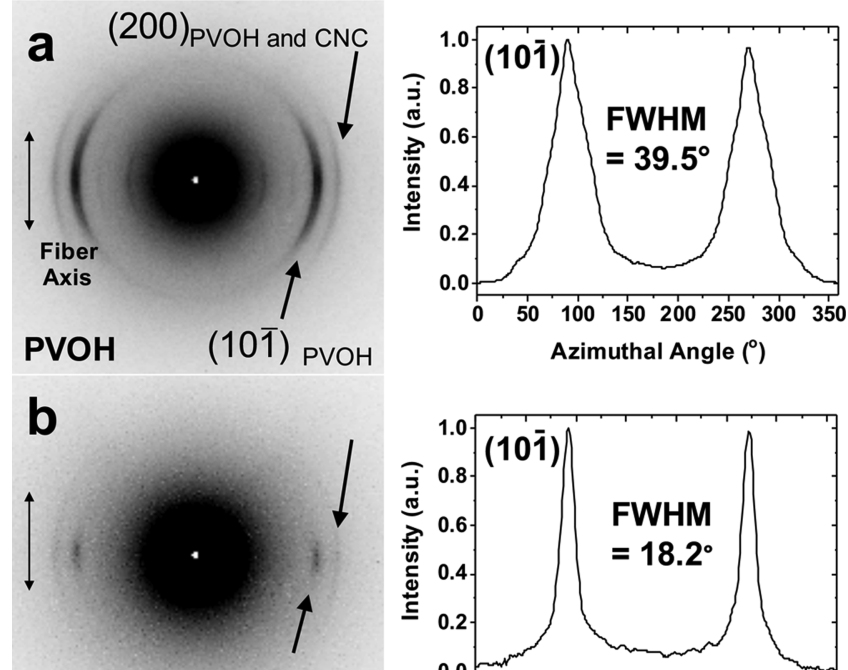

\section{CNC20/PVOH}

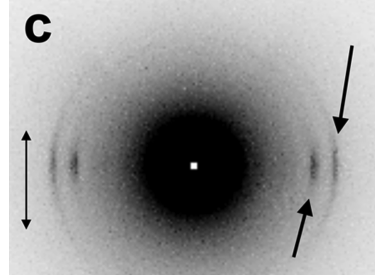

\section{CNC40/PVOH}

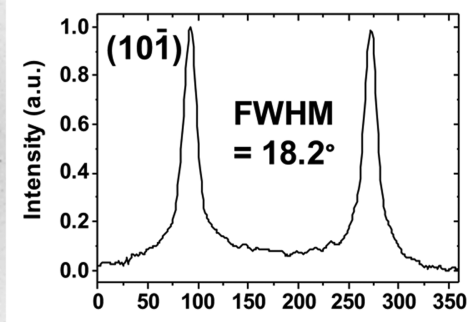
Azimuthal Angle $\left({ }^{\circ}\right)$

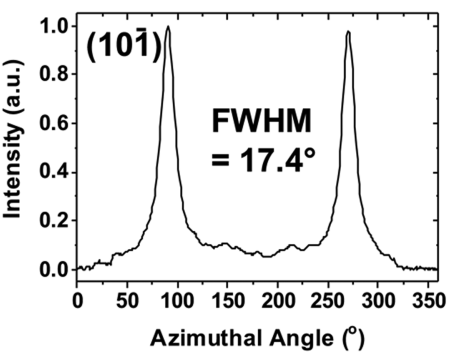

Figure 3. 2D WAXS pattern (left) and angular scattered intensity at $2 \theta$

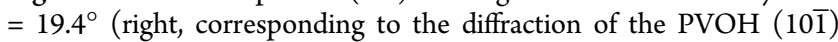
crystal plane): (a) PVOH, (b) $\mathrm{CNC} 20 / \mathrm{PVOH}$, and (c) $\mathrm{CNC} 40 /$

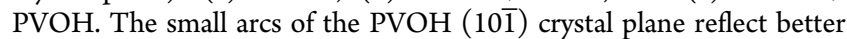
alignment of the PVOH chains in the presence of CNCs. FWHM (full width at half-maximum) was calculated based on Lorentzian fits.

PVOH (200) peak at $22.7^{\circ}$, preventing quantification of the $\mathrm{CNC}$ alignment. However, the intensity of the peak in this region does increase with $\mathrm{CNC}$ content and shows a qualitatively similar angular distribution to the $19.4^{\circ}$ peak, indicating that the alignment of the PVOH crystals and the $\mathrm{CNC}$ are correlated (WAXS, Figure $\mathrm{S} 5 \mathrm{e}-\mathrm{g}$ ).

As-spun $\mathrm{PVOH}$ and $\mathrm{CNC} / \mathrm{PVOH}$ fibers exhibit ductile deformation behavior, characteristic for low crystallinity $\mathrm{PVOH}$ materials, which are plasticized at $64 \%$ relative humidity. ${ }^{18}$ To compensate for variations in cross-sectional area and shape, the mechanical properties were evaluated relative to linear density, measured in N/tex, as conventional for textile fibers. Values in $\mathrm{N} /$ tex were converted to values in GPa, using the fiber average cross-sectional area deduced from the ratio of the measured linear density and calculated bulk density. ${ }^{2,9}$ While data in N/ tex may be considered more reliable, the conversion to GPa is useful for comparison with previous literature on CNC composites and other materials (see below). The tenacity and stiffness for as-spun PVOH fibers were $0.03 \mathrm{~N} / \operatorname{tex}(50 \mathrm{MPa})$ and $0.83 \mathrm{~N} /$ tex $(1.2 \mathrm{GPa})$, respectively, with a high strain to failure (500\%). The incorporation of CNCs increased both tenacity and stiffness $(\sigma=0.06 \mathrm{~N} / \mathrm{tex}(85 \mathrm{MPa}), E=1.1 \mathrm{~N} /$ tex $(1.6 \mathrm{GPa}))$. After hot-drawing (at a constant draw ratio of 6), the mechanical properties of all fibers increased dramatically at the expense of strain-to-failure (stress-strain data, Figure 4, and tabulated tensile properties, Figure S6). The ultimate tenacity and stiffness of the hot-drawn pure $\mathrm{PVOH}$ fibers increased to $0.3 \mathrm{~N} /$ tex $(430 \mathrm{MPa})$ and $5.5 \mathrm{~N} /$ tex $(8.3 \mathrm{GPa})$, respectively, at a strain to failure of $33.7 \pm 0.5 \%$. Optimized commercial pure PVOH fibers (Kuralon K-II WN2, $\sigma=0.6$ $\mathrm{N} /$ tex $(820 \mathrm{MPa}), E=17.7 \mathrm{~N} /$ tex (15 GPa), and $\varepsilon=20 \%)$ still have better properties because of the higher draw ratios $(\sim 20)$ possible at higher temperatures $\left(220^{\circ} \mathrm{C}\right) .{ }^{19}$ In the current experiments, the hot-drawing temperature was limited to 150 ${ }^{\circ} \mathrm{C}$ due to the onset of CNC degradation. ${ }^{14}$ Nevertheless, the hot-drawn PVOH fibers containing 40 wt \% CNC match the ultimate tenacity but have double the stiffness of the commercial material, with stiffness $21.1 \mathrm{~N} /$ tex $(29.9 \mathrm{GPa})$ and a tenacity $0.65 \mathrm{~N} / \operatorname{tex}(880 \mathrm{MPa})$ at a strain-to-failure of 5.6 $\pm 0.2 \%$. Mechanical properties increased with $\mathrm{CNC}$ loading up to $40 \mathrm{wt} \%$ (CNC40/PVOH) but decreased for a CNC loading of $60 \mathrm{wt} \%$ due to the agglomeration effects noted above (Figure $4 \mathrm{~b}, \mathrm{c}$ ). The increase in stiffness and tenacity for composite fibers with up to $40 \mathrm{wt} \% \mathrm{CNC}$ loading can be attributed to the combined effect of increased crystallinity of the matrix and direct reinforcement by the CNCs. To explore this hypothesis quantitatively, Krenchel's micromechanical model can be applied (eq 1$).{ }^{20}$ The model follows a rule of mixture formalism, modified for fiber length and orientation.

$$
E=\eta_{\mathrm{o}} \eta_{l} V_{\mathrm{f}} E_{\mathrm{f}}+V_{\mathrm{m} . \mathrm{a}} E_{\mathrm{m} . \mathrm{a}}+V_{\mathrm{m} . \mathrm{e}} E_{\mathrm{m} . \mathrm{c}}\left(V_{\mathrm{f}}+V_{\mathrm{m} . \mathrm{a}}+V_{\mathrm{m} . \mathrm{c}}=1\right)
$$

where $E_{\mathfrak{f}} E_{\mathrm{m} . a}$ and $E_{\mathrm{m} . \mathrm{c}}$ are the moduli of the CNC (120 GPa), amorphous matrix $(3.75 \mathrm{GPa})$, and crystalline matrix $(25.5$ $\mathrm{GPa})$, and $\eta_{\mathrm{o}}$ and $\eta_{1}$ efficiency factors relating to fiber orientation and length, respectively; the equation has been modified to treat the crystalline and amorphous $\mathrm{PVOH}$ components separately, to account for the changing levels of crystallinity between samples (see Appendix 1 in the Supporting Information for full derivation). The volume fractions are determined from weight fractions and the material densities $\left(1.26 \mathrm{~g} / \mathrm{cm}^{3}\right.$ for amorphous $\mathrm{PVOH}, 1.34 \mathrm{~g} / \mathrm{cm}^{3}$ for crystalline PVOH and $1.6 \mathrm{~g} / \mathrm{cm}^{3}$ for $\left.\mathrm{CNC}\right)^{2,9}$ and the degree of PVOH crystallinity, which was determined by DSC (Figure S4). Orientation factors for the PVOH crystals determined

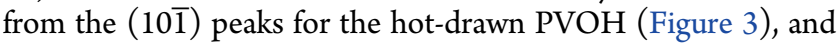
composite fibers containing 20 and 40 wt \% CNC, were calculated to be $0.73,0.83$, and 0.84 , respectively. The orientation efficiency factor of $\mathrm{CNC}$ was assumed to be the same as the degree of orientation of the $\mathrm{PVOH}$ as more detailed analysis was precluded due to peak overlap. The fiber length factor was calculated using the shear-lag model using the measured $\mathrm{CNC}$ length distribution from previous work. ${ }^{28}$ To be consistent with volume fraction terms used in the model, and the known moduli of the constituent phases, the stiffness of the composite fibers was normalized by area rather than linear density. The model predictions are in reasonably good agreement with the measured moduli (Figure 4c). The divergence at the highest $\mathrm{CNC}$ content correlates with the onset of CNC agglomeration. The general fit for the nanocomposite fibers containing well dispersed $\mathrm{CNCs}$, suggests that both CNC reinforcement and matrix crystallinity (which is also affected by the CNC loading fraction) do indeed play a role. For example, the relative increase in stiffness $(31.6 \mathrm{GPa})$ obtained for the sample containing $40 \mathrm{wt} \% \mathrm{CNC}$, above the value of the pure PVOH fiber $(6.5 \mathrm{GPa})$, is attributed partly to the stiffening contribution of the CNCs $(26.6 \mathrm{GPa})$ and partly to the increase in crystallinity (from 12.8 to $17.9 \%$ ) contributing an increase in stiffness of 5.0 GPa. 
a

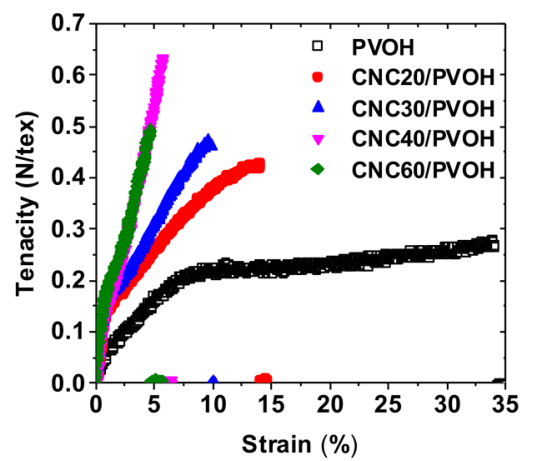

C

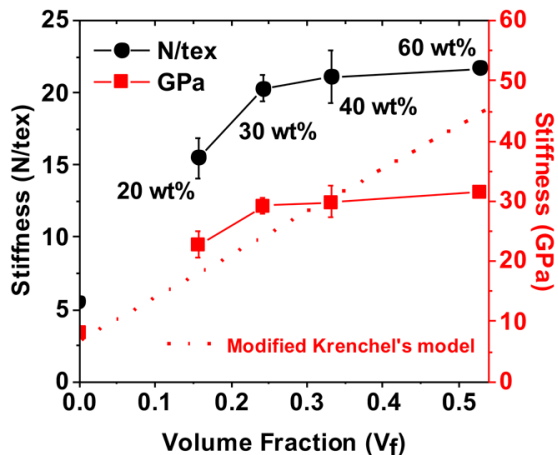

b
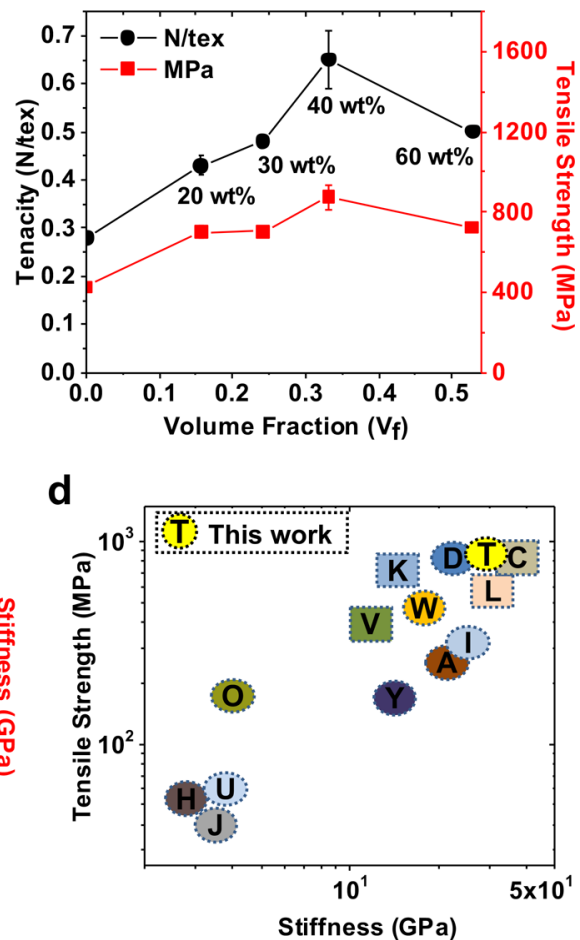

Figure 4. (a) Characteristic tenacity-strain curves of all $\mathrm{CNC} / \mathrm{PVOH}$ composite fibers and the pure PVOH control; all fibers were drawn to the same draw ratio (6). (b) Comparative mechanical strength of all $\mathrm{CNC} / \mathrm{PVOH}$ composite fibers and the pure $\mathrm{PVOH}$ control in textile and materials units. (c) Comparative mechanical stiffness of all $\mathrm{CNC} / \mathrm{PVOH}$ composite fibers and the pure $\mathrm{PVOH}$ control with modified Krenchel's model (in GPa). (d) Overview of strength vs stiffness of various nanocellulose-based composite fibers reported in scientific literature and commercially available fibers. Circles and rectangles indicate literature and commercial data, respectively. Tensile strength and stiffness were determined using the cross-sectional area, calculated by $\delta_{\mathrm{L}} / \delta_{\mathrm{B}}$, where $\delta_{\mathrm{L}}$ and $\delta_{\mathrm{B}}$ are linear and bulk density, respectively. Legend for data in D: C, Cordenka EHM; ${ }^{21} \mathrm{~K}$, Kuralon; L, Lyocelli ${ }^{22} \mathrm{~V}$, Viscose; ${ }^{22} \mathrm{~W}, \mathrm{CNF}, 2014 ;^{23} \mathrm{D}, \mathrm{CNF}, 2014{ }^{24} \mathrm{I}, \mathrm{CNF}, 2011 ;^{25} \mathrm{~A}, \mathrm{CNF}, 2011 ;^{26} \mathrm{Y}, \mathrm{CA} / \mathrm{CNC}, 2014 ;^{27} \mathrm{O}, \mathrm{PLA} / \mathrm{CNC}$, 2016; U, CNF/PVOH, 2008; ${ }^{28} \mathrm{H}, \mathrm{CNC} / \mathrm{PVOH}, 2015 ;^{29} \mathrm{~J}, \mathrm{CNC}, \mathrm{PVOH}, 2014 ;^{12}$ and T, This work

The stiffness and strength of the new $\mathrm{CNC} / \mathrm{PVOH}$ fiber exceed the properties of other nanocellulose-based fibers reported in the scientific literature (Figure 4d). Strikingly, our new fibers are approximately 10 times stronger than previous $\mathrm{CNC}$ composite fibers. Interestingly, their performance is quite similar to optimized commercially available, pure cellulose fibers, including Cordenka EHM $(\sigma=900 \mathrm{MPa}$ and $E=38$ $\mathrm{GPa}^{21}$ and Lyocell $\mathrm{A}(\sigma=624 \mathrm{MPa}$ and $E=31.2 \mathrm{GPa}){ }^{22}$ while exceeding those of Viscose $(\sigma=260 \mathrm{MPa}$ and $E=9.3$ $\mathrm{GPa}),{ }^{21}$ both in terms of stiffness and ultimate tensile strength. Because of the lower density of PVOH $\left(\sim 1.26-1.34 \mathrm{~g} / \mathrm{cm}^{3}\right)$ compared to pure cellulose $\left(1.5 \mathrm{~g} / \mathrm{cm}^{3}\right),{ }^{2,9}$ the $\mathrm{CNC} 40 / \mathrm{PVOH}$ fibers even outperform Cordenka EHM in terms of specific ultimate tensile strength $\left(0.62 \mathrm{GPa} \mathrm{cm}^{3} / \mathrm{g}\right.$ versus $0.60 \mathrm{GPa}$ $\left.\mathrm{cm}^{3} / \mathrm{g}\right)$. The ductile $\mathrm{PVOH}$ matrix also offers a higher elongation at break (5.5\% versus $4.6 \%) .^{21}$ Although singlewalled carbon nanotubes are reported to offer greater reinforcement in $\mathrm{PVOH}$ fibers, ${ }^{13}$ because of their superior mechanical properties, they are not renewable, are less environmentally benign, and are harder to process than CNCs. The relative success of the CNCs can be attributed to their excellent hydrogen-bonding compatibility with $\mathrm{PVOH}^{30}$

Interestingly, the presence of the CNCs appears to dramatically improve the polymer microstructure, even under relatively modest drawing conditions. The size and stiffness of the CNCs is expected to assist their orientation by shear, due to longer rotational relaxation times. The coaxial flow coagulation spinning process appears to be very effective at orienting both components. Once oriented, the CNCs encourage the nucleation of $\mathrm{PVOH}$ crystals, increasing both polymer crystallinity and orientation. Despite the lower crystallinity of $\mathrm{PVOH}$ in this composite, compared to commercial $\mathrm{PVOH}$ ( 50-60\%), the higher fiber stiffness shows that the CNCs are contributing effectively. The overall improvement in properties is thus likely to be a combination of improved polymer microstructure and direct reinforcement by the CNCs. The results obtained are extremely promising, and offer considerable scope for further optimization of constituents and processing conditions. To date, the development of CNC composites has been hampered by the poor mechanical performance obtained in most cases. The high performance obtained here demonstrates that further development is warranted. The highly aligned, high loading CNC reinforced fibers may have direct relevance to biomedical applications due to their biocompatibility. In addition, they could be readily combined with a suitable (renewable) matrix to create a new generation of hierarchical composites.

\section{ASSOCIATED CONTENT}

\section{Supporting Information}

The Supporting Information is available free of charge on the ACS Publications website at DOI: 10.1021/acsami.6b11578.

Detailed experimental procedures, optical microscopic images, DSC thermograms, XRD diffraction patterns, tenacity-strain curves, and SEM images (PDF) 


\section{AUTHOR INFORMATION}

\section{Corresponding Author}

*E-mail: m.shaffer@imperial.ac.uk. Tel: +44 (0)20 75945825.

Notes

The authors declare no competing financial interest.

\section{ACKNOWLEDGMENTS}

We are grateful to Dr. Hannah S. Leese, Dr. David. B. Anthony (Imperial College London), and Dr. Andreas Mautner (University of Vienna) for their help with various experiments. This work was funded under the UK Engineering and Physical Sciences Research Council (EPSRC) Programme Grant EP/ I02946X/1 on High Performance Ductile Composite Technology in collaboration with University of Bristol. Supporting data can be requested from the corresponding author, but may be subject to confidentiality obligations. Eero Kontturi acknowledges Academy of Finland (Grant 259500). Adam J. Clancy acknowledges Doctoral Training Partnership (EP/M507878/ 1).

\section{REFERENCES}

(1) Habibi, Y.; Lucia, L. A.; Rojas, O. J. Cellulose nanocrystals: Chemistry, self-assembly, and applications. Chem. Rev. 2010, 110 (6), 3479-3500.

(2) Dufresne, A. Nanocellulose: a new ageless bionanomaterial. Mater. Today 2013, 16 (6), 220-227.

(3) Lee, K. Y.; Tammelin, T.; Schulfter, K.; Kiiskinen, H.; Samela, J.; Bismarck, A. High performance cellulose nanocomposites: Comparing the reinforcing ability of bacterial cellulose and nanofibrillated cellulose. ACS Appl. Mater. Interfaces 2012, 4 (8), 4078-4086.

(4) Giese, M.; Blusch, L. K.; Khan, M. K.; MacLachlan, M. J. Functional Materials from Cellulose-Derived Liquid-Crystal Templates. Angew. Chem., Int. Ed. 2015, 54 (10), 2888-2910.

(5) Lagerwall, J. P. F.; Schutz, C.; Salajkova, M.; Noh, J.; Hyun Park, J.; Scalia, G.; Bergstrom, L. Cellulose nanocrystal-based materials: from liquid crystal self-assembly and glass formation to multifunctional thin films. NPG Asia Mater. 2014, 6, e80.

(6) Bledzki, A. K.; Gassan, J. Composites reinforced with cellulose based fibres. Prog. Polym. Sci. 1999, 24 (2), 221-274.

(7) Mujica-Garcia, A.; Hooshmand, S.; Skrifvars, M.; Kenny, J. M.; Oksman, K.; Peponi, L. Poly(lactic acid) melt-spun fibers reinforced with functionalized cellulose nanocrystals. RSC Adv. 2016, 6 (11), 9221-9231.

(8) Khoshkava, V.; Kamal, M. R. Effect of Surface Energy on Dispersion and Mechanical Properties of Polymer/Nanocrystalline Cellulose Nanocomposites. Biomacromolecules 2013, 14 (9), 31553163.

(9) Peppas, N. A.; Merrill, E. W. Poly(vinyl alcohol) hydrogels: Reinforcement of radiation-crosslinked networks by crystallization. J. Polym. Sci., Part A: Polym. Chem. 1976, 14 (2), 441-457.

(10) Peresin, M. S.; Habibi, Y.; Zoppe, J. O.; Pawlak, J. J.; Rojas, O. J. Nanofiber Composites of Polyvinyl Alcohol and Cellulose Nanocrystals: Manufacture and Characterization. Biomacromolecules 2010, 11 (3), 674-681.

(11) Paralikar, S. A.; Simonsen, J.; Lombardi, J. Poly(vinyl alcohol)/ cellulose nanocrystal barrier membranes. J. Membr. Sci. 2008, 320 (12), 248-258.

(12) Liu, D.; Li, J.; Sun, F.; Xiao, R.; Guo, Y.; Song, J. Liquid crystal microphase separation of cellulose nanocrystals in wet-spun PVA composite fibers. RSC Adv. 2014, 4 (58), 30784-30789.

(13) Vigolo, B.; Pénicaud, A.; Coulon, C.; Sauder, C.; Pailler, R.; Journet, C.; Bernier, P.; Poulin, P. Macroscopic Fibers and Ribbons of Oriented Carbon Nanotubes. Science 2000, 290 (5495), 1331-1334.

(14) Bardet, R.; Belgacem, N.; Bras, J. Flexibility and Color Monitoring of Cellulose Nanocrystal Iridescent Solid Films Using
Anionic or Neutral Polymers. ACS Appl. Mater. Interfaces 2015, 7 (7), 4010-4018.

(15) Miaudet, P.; Badaire, S.; Maugey, M.; Derré, A.; Pichot, V.; Launois, P.; Poulin, P.; Zakri, C. Hot-Drawing of Single and Multiwall Carbon Nanotube Fibers for High Toughness and Alignment. Nano Lett. 2005, 5 (11), 2212-2215.

(16) Cho, J. D.; Lyoo, W. S.; Chvalun, S. N.; Blackwell, J. X-ray Analysis and Molecular Modeling of Poly(vinyl alcohol)s with Different Stereoregularities. Macromolecules 1999, 32 (19), 62366241.

(17) Nishiyama, Y.; Langan, P.; Chanzy, H. Crystal Structure and Hydrogen-Bonding System in Cellulose I $\beta$ from Synchrotron X-ray and Neutron Fiber Diffraction. J. Am. Chem. Soc. 2002, 124 (31), 9074-9082.

(18) Hodge, R. M.; Edward, G. H.; Simon, G. P. Water absorption and states of water in semicrystalline poly(vinyl alcohol) films. Polymer 1996, 37 (8), 1371-1376.

(19) Wyatt, T. P.; Chien, A.-T.; Kumar, S.; Yao, D. Development of a gel spinning process for high-strength poly(ethylene oxide) fibers. Polym. Eng. Sci. 2014, 54 (12), 2839-2847.

(20) Coleman, J. N.; Cadek, M.; Blake, R.; Nicolosi, V.; Ryan, K. P.; Belton, C.; Fonseca, A.; Nagy, J. B.; Gun'ko, Y. K.; Blau, W. J. High Performance Nanotube-Reinforced Plastics: Understanding the Mechanism of Strength Increase. Adv. Funct. Mater. 2004, 14 (8), 791-798.

(21) Northolt, M. G.; Boerstoel, H.; Maatman, H.; Huisman, R.; Veurink, J.; Elzerman, H. The structure and properties of cellulose fibres spun from an anisotropic phosphoric acid solution. Polymer 2001, 42 (19), 8249-8264.

(22) Gindl, W.; Reifferscheid, M.; Adusumalli, R. B.; Weber, H.; Röder, T.; Sixta, H.; Schöberl, T. Anisotropy of the modulus of elasticity in regenerated cellulose fibres related to molecular orientation. Polymer 2008, 49 (3), 792-799.

(23) Håkansson, K. M. O.; Fall, A. B.; Lundell, F.; Yu, S.; Krywka, C.; Roth, S. V.; Santoro, G.; Kvick, M.; Prahl Wittberg, L.; Wågberg, L.; Söderberg, L. D. Hydrodynamic alignment and assembly of nanofibrils resulting in strong cellulose filaments. Nat. Commun. 2014, 5, 4018.

(24) Peng, J.; Ellingham, T.; Sabo, R.; Turng, L.-S.; Clemons, C. M. Short cellulose nanofibrils as reinforcement in polyvinyl alcohol fiber. Cellulose 2014, 21 (6), 4287-4298.

(25) Iwamoto, S.; Kai, W.; Isogai, A.; Iwata, T. Elastic Modulus of Single Cellulose Microfibrils from Tunicate Measured by Atomic Force Microscopy. Biomacromolecules 2009, 10 (9), 2571-2576.

(26) Walther, A.; Timonen, J. V. I; Díez, I.; Laukkanen, A.; Ikkala, O. Multifunctional High-Performance Biofibers Based on Wet-Extrusion of Renewable Native Cellulose Nanofibrils. Adv. Mater. 2011, 23 (26), 2924-2928.

(27) Chen, S.; Schueneman, G.; Pipes, R. B.; Youngblood, J.; Moon, R. J. Effects of Crystal Orientation on Cellulose NanocrystalsCellulose Acetate Nanocomposite Fibers Prepared by Dry Spinning. Biomacromolecules 2014, 15 (10), 3827-3835.

(28) Tang, C.; Liu, H. Cellulose nanofiber reinforced poly(vinyl alcohol) composite film with high visible light transmittance. Composites, Part A 2008, 39 (10), 1638-1643.

(29) Sirviö, J. A.; Honkaniemi, S.; Visanko, M.; Liimatainen, H. Composite Films of Poly(vinyl alcohol) and Bifunctional Cross-linking Cellulose Nanocrystals. ACS Appl. Mater. Interfaces 2015, 7 (35), 19691-19699.

(30) Zhang, W.; He, X.; Li, C.; Zhang, X.; Lu, C.; Zhang, X.; Deng, Y. High performance poly (vinyl alcohol)/cellulose nanocrystals nanocomposites manufactured by injection molding. Cellulose 2014, 21 (1), 485-494. 